\title{
STUDY OF HIGH-RISK SEXUAL BEHAVIOUR AND ASSOCIATED PSYCHIATRIC DISORDER (ADHD) AMONG FEMALE SEX WORKERS
}

\author{
Kasthuri Pandiyan', Asha Latha $M^{2}$
}

1 Professor, Department of Psychiatry, MVJ\&RH Medical College, Hoskote, Bangalore, Karnataka, India.

${ }^{2}$ Assistant Professor, Department of Psychiatry, KIMS Medical College and Research Hospital, Bangalore, Karnataka, India.

\begin{tabular}{l}
\hline ABSTRACT \\
A numGROUND of psychiatric morbidities are known to contribute to risky sexual behavior. There is a link between ADHD and risky \\
sexual behavior. This study aimed to find the prevalence of ADHD and associated psychiatric morbidity among female sex workers \\
and the prevalence of high risk sexual behaviour.
\end{tabular}

\section{MATERIALS AND METHODS}

96 consenting female sex workers were recruited into the study and were administered the following questionnaires Adult ADHD Self-Report Scale (ASRS), Wender Utah rating scale (WURS) for retrospective childhood diagnosis for ADHD, MINI neuropsychiatric interview, HIV Risk behaviour scale (HRBS), Beck's depression inventory (BDI), Presumptive stressful life events scale (PSLES). Statistical analysis was done using SPSS v19.

\section{RESULTS}

The prevalence of Adult ADHD in the sample was $32.2 \%(n=31)$. Those with ADHD had significantly higher prevalence of risky sexual behaviors $(\mathrm{p}=0.02)$, depression $(\mathrm{p}=0.04)$, stress levels $(\mathrm{p}=0.001)$ and overall prevalence of STIs $(\mathrm{p}=0.03)$.

\section{CONCLUSION}

There is a high prevalence of risky sexual behaviors among female sex workers. This could be accounted for by higher psychiatric comorbidities such as depression, higher stress and ADHD, which is less frequently understood. Future studies should look at $\mathrm{ADHD}$ as a possible preventive factor for high risk sexual behavior in this population.

\section{KEY WORDS}

Attention Deficit Disorder with Hyperactivity, Female, Sex Workers, Risk-Taking, Sexual Behavior.

HOW TO CITE THIS ARTICLE: Pandiyan K, Latha AM. Study of high-risk sexual behaviour and associated psychiatric disorder (ADHD) among female sex workers. J. Evolution Med. Dent. Sci. 2019;8(05):326-328, DOI: 10.14260/jemds/2019/70

\section{BACKGROUND}

Female commercial sex workers (CSWs) are defined as those females who provide sexual services for payment in cash or kind in the last one month (NACO, INDIA).(1) Many psychosocial adversities contribute to individuals taking up sex work as a profession. A significant number of them are found to have psychiatric morbidity such as substance dependence, depression.(2) An additional comorbidity recently being explored is Attention Deficit Hyperactivity Disorder (ADHD). Studies have indicated that ADHD was linked with early sexual debut or failure to use condoms. (3) One study reported that men who had childhood ADHD were more likely than men without ADHD to report casual sex, infrequent condom use, and multiple sex partners.(4) Most ADHD studies have focused on male participants, leading to calls for studies of ADHD-related outcomes among women.(5) A previous study has indicated that the prevalence of ADD among female sex workers was around $34 \%$ but the study had low sample size.(6)

'Financial or Other Competing Interest': None.

Submission 23-11-2018, Peer Review 21-01-2019,

Acceptance 28-01-2019, Published 04-02-2019.

Corresponding Author:

Dr. Asha Latha $M$,

Assistant Professor

Department of Psychiatry,

KIMS Medical College and Research Hospital,

Bangalore, V. V. Puram, Karnataka, India.

E-mail: molagavelli@gmail.com

DOI: $10.14260 /$ jemds $/ 2019 / 70$
Another study done on females has identified that persistent impulsivity with added risk factors like poor maternal attachment, symptoms of CD was associated with high risk sexual behaviour among young women.(4) Thus, ADHD may be associated with risky sexual behaviour which is known to be the main causative factor for sexually transmitted infections(STIs). A previous study has reported a prevalence of $20 \%$ of young men who were newly diagnosed to have HIV having ADHD symptoms. (7)

\section{Aims and Objectives}

This cross-sectional study sought to find the prevalence of ADHD, high risk sexual behaviour and presence of psychiatric comorbidity in commercial sex workers in Bangalore city.

\section{MATERIALS AND METHODS}

It was a cross sectional study carried out at the Psychiatry outpatient clinic of a tertiary care hospital in Bangalore, India. The majority of participants were recruited through voluntary agencies providing counseling services to sex workers $(n=86)$. The remaining 10 participants were introduced to the study by chain referral through participants' associates. A majority of participants (70\%) were from Bangalore. All participants were asked to register their understanding and consent to participate in the study by oral consent signed in the form by an impartial witness. 96 eligible participants took part in the study. Interviews were conducted at Victoria hospital Bangalore. The interview was conducted by the principal investigator in a place which ensures visual and auditory privacy. Each interview lasted for about 2 hours. 


\section{Inclusion Criteria}

Female sex workers who have sold sex in exchange for goods or money in the last one month, above the age of 18 providing oral consent.

\section{Exclusion Criteria}

Participants who are critically ill and whose mental status does not allow them to comprehend the questions and respond.

These participants were then administered the following scales and questionnaires

1. A semi-structured interview was used to elicit the following details- Socio demographic data: Age, residence, marital status, educational status, employment status, income, number of living children. Other details of sexual behaviour, substance use, lower urinary tract symptoms and symptoms of sexually transmitted diseases were confirmed with a venereology consultation which included investigations such as urine routine, culture, urethral smear, VDRL, ELISA-HIV. The ethical clearance was taken from hospital ethical committee.

2. Adult ADHD Self-Report Scale (ASRS) was used to screen for ADHD symptoms. The ASRS was developed by the World Health Organization and the short form of the screener consists of a checklist of six questions regarding symptoms of ADHD based on the diagnostic criteria of DSM-IV-TR. Each item requires respondents to rate on a five-point response scale from "Never" [0] to "Very often". [4] how frequently a particular symptom of ADHD occurred over the past six months.(8) A cut-off of 14 for the first 6 items of the screener was used as described by Kessler, 2007.(9) In addition, as described by Kessler, subjects who scored a total of 9 or more of the shaded boxes of the whole scale were only considered as having symptoms of ADHD.

3. Wender Utah rating scale (WURS) was used to assess presence of childhood ADHD symptoms. A diagnosis of ADHD was made if an individual scored over a cut-off of 24 on the ASRS with a WURS score of 46 or above indicating presence of ADHD symptoms in childhood in those individuals who scored above the cut-off on ASRS.(10)

4. HIV risk behaviour scale (HRBS) was used to screen for high risk sexual behaviour.(11)

5. MINI neuropsychiatric interview was used to screen for presence of psychiatric co morbidities.(12)

6. Beck's Depression inventory 2 (Self-rated) was used to assess the severity of depression when present.(13)

7. Presumptive stressful life events scale (PSLES) was used to generate a score for the stressful life events.(14)

Statistical analysis was done using SPSS v 19.

\section{RESULTS}

Prevalence of ADHD symptoms in the study population-(ASRS cut off 24$)=(n=31), 32.2 \%$.

\begin{tabular}{|c|c|c|}
\hline & Mean & Standard Deviation (SD) \\
\hline Age (yrs.) & 39.9 & 7.3 \\
\hline Years of Education & 3.6 & 4.3 \\
\hline Income (Rupees) & 13774 & 3307.2 \\
\hline \multicolumn{2}{|c|}{ Table 1. Socio-Demographic Characteristics of } \\
\multicolumn{2}{|c|}{ The Sample } \\
\hline
\end{tabular}

\begin{tabular}{|c|c|c|c|}
\hline & $\begin{array}{c}\text { ADHD } \\
\text { (n=31) }\end{array}$ & $\begin{array}{c}\text { No ADHD } \\
\text { (n=65) }\end{array}$ & p Value \\
\hline $\begin{array}{c}\text { Consistent } \\
\text { Condom Use }\end{array}$ & 5 & 56 & $0.001^{* * *}$ \\
\hline $\begin{array}{c}\text { More than 5 } \\
\text { Partners }\end{array}$ & 11 & 24 & 0.11 \\
\hline Group Sex & 11 & 14 & 0.09 \\
\hline $\begin{array}{c}\text { Injection Use } \\
\text { Prior To Sex }\end{array}$ & 4 & 12 & 0.10 \\
\hline $\begin{array}{c}\text { Alcohol Use Prior } \\
\text { To Sex }\end{array}$ & 12 & 24 & $0.02^{*}$ \\
\hline \multicolumn{4}{|c|}{ Table 2. High Risk Sexual Behaviours of The } \\
Sample \\
\hline
\end{tabular}

Those with ADHD had less consistent condom use and alcohol use prior to sex than those without ADHD.

\begin{tabular}{|c|c|c|c|}
\hline & $\begin{array}{c}\text { ADHD } \\
\text { (n=31) }\end{array}$ & $\begin{array}{c}\text { No ADHD } \\
\text { (n=65) }\end{array}$ & p Value \\
\hline $\begin{array}{c}\text { Beck's Depression } \\
\text { Inventory Presumptive }\end{array}$ & 19.92 & 14.53 & $0.04^{*}$ \\
\hline Stressful Life Events Scale & 294.9 & 245.4 & $0.001^{* *}$ \\
\hline HIV Risk Behaviour Scale & 4.53 & 4.12 & 0.12 \\
\hline \multicolumn{4}{|c|}{ Table 3. Comparison of Comorbidities in Those } \\
With and Without ADHD \\
\hline
\end{tabular}

Those with ADHD significantly had more depression and higher stressful life events score than those without ADHD.

\begin{tabular}{|c|c|c|}
\hline & Correlation Coefficient (r) & p value \\
\hline BDI vs HRBS & 0.28 & 0.26 \\
\hline PSLES vs HRBS & 0.34 & $0.04^{*}$ \\
\hline ADHD vs HRBS & 0.78 & $0.001^{* *}$ \\
\hline \multicolumn{2}{|r|}{ Table 4. Correlations of Scores with Risky Sexual } \\
Behaviour
\end{tabular}

Both ADHD scores and stress scores had a significant correlation with risky sexual behaviour.

\begin{tabular}{|c|c|c|}
\hline & ADHD (n=31) & No ADHD (n=65) \\
\hline HIV & 3 & 0 \\
\hline Herpes Genitalis & 4 & 9 \\
\hline Syphilis & 3 & 1 \\
\hline Others & 4 & 7 \\
\hline Total & 14 & 17 \\
\hline
\end{tabular}

Those with ADHD had significantly higher prevalence of STIs overall $\left(\mathrm{p}=0.03^{*}\right)$. Overall prevalence of those with any STI in the sample was $26.04 \%(n=25)$. Only those with ADHD had HIV. "Others" included those with gonorrhoea, lymphogranuloma venereum, molluscum. 


\section{DISCUSSION}

1. There was a very high prevalence of ADHD symptoms among this sample of sex workers $(n=31,32.2 \%)$. This could be because those with ADHD are predisposed to develop high risk behaviours of which risky sexual behaviour is important. Also, those with ADHD frequently have other psychiatric co-morbidities such as depression.(2) substance use.(15) which further increases the risk. (The mean BDI score and HRBS scores are also high which reflects the same).

2. Majority of the sample had high risk sexual behaviours such as group sex, inconsistent condom use, higher number of partners, injection and alcohol use prior to sex. Reasons as stated by a few of them were that the clients pay more when condoms were not used (In spite of them reporting that they had knowledge of safe sexual practices). It was also seen that those with ADHD had less consistent condom use and higher frequency of alcohol use prior to sex. This could reflect possible lack of behavioural inhibition as reported by Barkeley.(16) which contributes to impulsivity and risk taking behaviours.

3. Those with ADHD also had higher prevalence of depression and stress than those without ADHD. ADHD is known to be comorbid with depression.(2) and other factors such as executive impairments seen in ADHD.(16) could increase perceived stress. These factors could thus also contribute to risky sex as reflected by good correlation of ADHD scores and stress scores to risky sexual behavior in the sample.

4. The overall prevalence of those with any STI in the sample was $26.04 \%(n=25)$. Those with ADHD had significantly higher prevalence of STIs overall $\left(\mathrm{p}=0.03^{*}\right)$. Only those with ADHD had HIV. Thus, it could be speculated that ADHD is also a risk factor for STIs which is probably mediated by risky sexual behavior.

\section{Limitations}

1. Small sample size.

2. Cross-sectional study design.

3. The study sample was brought by counselors which could indicate that those taken up for the study already were having some psychiatric morbidity (Not an indicator of a community sample).

\section{CONCLUSION}

There is a high prevalence of STIs and risky sexual behaviors among female sex workers. This could be accounted for by higher psychiatric comorbidities such as depression, higher stress and ADHD, which is less frequently understood.

Future studies should look at ADHD as a possible preventive factor for STIs in this population.

\section{REFERENCES}

[1] Waterman N. Commercial sex work in Maseru: an exploratory study of public policy-making in Lesotho. Unpublished doctoral thesis. Durban: University of Kwazulu-Natal 2005.

[2] McIntosh D, Kutcher S, Binder C, et al. Adult ADHD and comorbid depression: a consensus-derived diagnostic algorithm for ADHD. Neuropsychiatric Disease and Treatment 2009;5:137-50.
[3] Barkley RA, Fischer M, Smallish L, et al. Young adult outcome of hyperactive children: adaptive functioning in major life activities. J Am Acad Child Adolesc Psychiatry 2006;45(2):192-202.

[4] Flory K, Molina BSG, Pelham WE Jr, et al. Childhood ADHD predicts risky sexual behavior in young adulthood. Journal of Clinical Child and Adolescent Psychology 2006;35(4):571-7.

[5] Brown LK, Hadley W, Stewart A, et al. Psychiatric disorders and sexual risk among adolescents in mental health treatment. J Consult Clin Psychol 2010;78(4):590-7.

[6] Pandiyan K, Kumar S, Hongally C. Prevalence of ADHD in women sex workers and other characteristics in OPD of a tertiary care. Journal of Research in Psychiatry and Behavioral Sciences 2015;1(1):21-4.

[7] Kumar S, Shekar A, Pandiyan K, et al. Prevalence of adult attention deficit hyperactivity disorder and its correlates among recently diagnosed young adult males with HIV. J AIDS Clin Res 2014;5:314.

[8] Kessler RC, Adler L, Ames M, et al. The world health organization adult ADHD self-report scale (ASRS): a short screening scale for use in the general population. Psychol Med 2005;35(2):245-56.

[9] Kessler RC, Adler LA, Gruber MJ, et al. Validity of the World Health Organization Adult ADHD Self-Report Scale (ASRS) screener in a representative sample of health plan members. International Journal of Methods in Psychiatric Research 2007;16(2):52-65.

[10] Ward MF, Wender PH, Reimherr FW. The Wender Utah Rating Scale: an aid in the retrospective diagnosis of childhood attention deficit hyperactivity disorder. Am J Psychiatry 1993;150(6):885-90.

[11] Darke S, Hall W, Heather N, et al. The reliability and validity of a scale to measure HIV risk-taking behaviour among intravenous drug users. AIDS 1991;5(2):181-5.

[12] Sheehan DV, Lecrubier Y, Sheehan KH, et al. The MiniInternational Neuropsychiatric Interview (M.I.N.I.): the development and validation of a structured diagnostic psychiatric interview for DSM-IV and ICD10. J Clin Psychiatry 1998;59(Suppl 20):22-33, quiz 34-57.

[13] Steer RA, Ball R, Ranieri WF, et al. Dimensions of the beck depression inventory-II in clinically depressed outpatients. Journal of Clinical Psychology 1999;55(1):117-28.

[14] Singh G, Kaur D, Kaur H. Presumptive Stressful Life Events Scale (PSLES)-a new stressful life events scale for use in India. Indian Journal of Psychiatry 1984;26(2):107-14.

[15] Mariani JJ, Levin FR. Treatment strategies for cooccurring ADHD and substance use disorders. The American Journal on Addictions/ American Academy of Psychiatrists in Alcoholism and Addictions 2007;16(Suppl 1):45-56.

[16] Barkley RA. Executive functioning and self-regulation: extended phenotype, synthesis and clinical implications. New York: Guilford Publications 212. 